\title{
EMPREENDEDORISMO: EVOLUÇÃO HISTÓRICA, DEFINIÇÕES E ABORDAGENS.*
}

\author{
Everton Verga - Universidade Estadual de Maringá ${ }^{1}$ \\ Luiz Fernando Soares da Silva - Universidade Estadual de Maringá ${ }^{2}$
}

\begin{abstract}
Resumo: Na difusão da compreensão e entendimento do fenômeno empreendedorismo, este trabalho busca apresentar o estudo de alguns aspectos relevantes e essenciais para o processo de aprendizagem sobre o termo empreendedorismo. São eles: a evolução histórica, os principais conceitos, definições e abordagens. Neste sentido, o objetivo principal foi apresentar o contexto histórico do assunto, bem como as evoluções do campo de pesquisa e seu contexto no desenvolvimento econômico. Com isso, o estudo pretendeu evidenciar por meio de um ensaio teórico, sua evolução e seus reflexos nas pesquisas acadêmicas e na sociedade. A metodologia utilizada foi a pesquisa exploratória de cunho bibliográfico, baseando-se em publicações de diversos Journals que fazem parte da base de dados da CAPES, como também os periódicos RAUSP e RAC, e anais do EGEPE e EnANPAD.
\end{abstract}

Palavras-chave: Empreendedorismo. Effectuation. Desenvolvimento Econômico.

\section{ENTREPRENEURSHIP: HISTORIC DEVELOPMENT, DEFINITIONS AND APPROACHES}

Abstract: In diffusion of the understanding of entrepreneurship phenomenon, this study aims to present the study of some relevant and essential aspects to the process of learning about the term entrepreneurship. They are: the historical evolution, main concepts, definitions and approaches. In this sense, the main objective was to present the historical context of this subject and also the evolution of the research field and its context in economic development. Thus, the study intended to demonstrate by means of a theoretical test, its evolution and its consequences in academic research and society. The methodology used was the exploratory research of bibliographic nature, based on several publications of Journals that are part of the CAPES database, as well as the journals of RAUSP and RAC, and proceedings of EGEPE and EnANPAD.

Keywords: Entrepreneurship. Effectuation. Economic Development.

\footnotetext{
*Artigo publicado originalmente no VIII Egepe e oriundo do fast track daquele evento

${ }^{1}$ E.mail: evertonverga@yahoo.com.br - Endereço: Av. Colombo, 5790, Bloco C23, Sala 15, Maringá - PR, CEP: 87020-900.

2 E.mail: dasilvauel@yahoo.com.br
}

VERGA, E.; SOARES DA SILVA, L. F. Empreendedorismo: evolução histórica, definições e abordagens. Revista de Empreendedorismo e Gestão de Pequenas Empresas, v. 3, n. 3, p. 3-30, 2014. 
Introdução

Sabe-se que após a queda de Roma (por volta de 476 d.C.) e até meados do século XVIII, praticamente não existiu aumentos na geração de riqueza. Contudo, com o advento do empreendedorismo, esse cenário mudou principalmente no Ocidente, apresentando um crescimento exponencial de 1700 a 1900. Assim, ao longo deste cenário, o pensamento empreendedor evoluiu, evidenciando a dimensão que o termo alcança, disseminando-se nas escolas de negócios e academias (MURPHY; LIAO; WELSCH, 2006).

Neste sentido, o interesse por seu estudo aumentou consideravelmente com uma comunidade científica reconhecida, expressando-se através de um grande número de conferências e publicações científicas (BRUYAT; JULIEN, 2000; MURPHY; LIAO; WELSCH, 2006; ALDRICH, 2012), mas persistindo ainda em questões relacionadas à necessidade de uma melhor compreensão científica deste tema.

Para Shane e Venkataraman (2000), é quase impossível o entendimento do assunto apenas por características pessoais, além de ser importante uma contextualização existente na influência de diversas situações e do próprio ambiente onde este fenômeno é desenvolvido. Shane (2003) enfatiza o estudo do empreendedorismo com uma abordagem interdisciplinar para a elaboração de um esquema conceitual que possa melhor compreender o assunto. Davidsson (2004) também afirma que a pesquisa sobre este termo não está focada apenas no surgimento de novas empresas, mas principalmente nos novos mercados e mudanças que ocorrem neles.

Assim, este trabalho tem como objetivo descrever a evolução das discussões sobre a conceituação do empreendedorismo no campo de estudo, frente a sua evolução histórica. Quanto à fonte de dados utilizada na pesquisa, destacamse os diversos Journals específicos sobre Entrepreneurship (Empreendedorismo), como: Small Business Economics; Journal of Business Venturing; Journal of Management; Academy of Management Review; Entrepreneurship Theory and Practice. Foram pesquisados periódicos nacionais como: Revista de Administração 
(RAUSP) e Revista de Administração Contemporânea (RAC). Por fim, consultou-se os anais do EGEPE e EnANPAD.

É importante ressaltar que os critérios de seleção dos trabalhos utilizados partiram da premissa dos que abordavam discussões sobre a evolução do empreendedorismo como campo de pesquisa, suas abordagens e perspectivas. A primeira parte do trabalho apresenta uma abordagem acerca da evolução histórica, seguido pela descrição do campo de pesquisa e uma das definições mais disseminadas na literatura recente sobre o termo empreendedorismo. Após essa discussão, são apresentadas as perspectivas processual e effectual, finalizando com a abordagem relacionada à influência do empreendedorismo no desenvolvimento econômico.

\section{EVOLUÇÃO, CONCEITOS E ABORDAGENS DO EMPREENDEDORISMO}

\section{EVOLUÇÃO E CONTEXTUALIZAÇÃO HISTÓRICA}

Mesmo que para muitos o campo de pesquisa em empreendedorismo seja relativamente novo, os pensamentos pioneiros sobre o termo não são. Segundo Landström, Harirchi, Aström (2012), provavelmente a função é tão antiga como o intercâmbio e o comércio entre os indivíduos na sociedade, mas, no entanto, este conceito não era discutido. Somente a partir da evolução dos mercados econômicos, os cientistas se interessaram pelo fenômeno.

Segundo Landström e Benner (2010), essa discussão ocorreu após um grande período de estagnação aplicado pelo sistema feudal na economia europeia, onde $\mathrm{o}$ direito de propriedade era restrito e os produtos altamente taxados. Entretanto, durante a Idade Média, essas condições se modificaram lentamente e o sistema de empreendedorismo evoluía com base nas classes dos comerciantes e na ascensão das cidades. Neste período, o termo empreendedor "foi usado para descrever tanto um participante quanto um administrador de grandes projetos de produção" (HISRICH; PETERS; SHEPHERD, 2009, p. 28).

Para Fillion (1999), Vérin, em 1982, foi um dos primeiros a estudar a evolução do termo enter-preneur através da história. É preciso observar que no século XII, 
este termo era usado para referir-se "àquele que incentiva brigas". Já no século XVII, representado pela era econômica, o empreendedor estava ligado à pessoa que "tomava a responsabilidade e coordenava uma operação militar", e no fim deste século e início do século XVIII, o termo foi usado como referência à pessoa que "criava e conduzia empreendimentos".

Murphy, Liao e Welsch (2006) destacam que a atividade empreendedora se expandiu ao longo séculos XVI e XVII com o conhecimento experimental e, portanto, epistemológico ou baseado nas habilidades, tornando-se cada vez mais instrumentais para corrigir as ineficiências ou fornecer novas soluções, bens e serviços. Com a especialização do conhecimento, a descoberta de oportunidades comerciais e a atividade empreendedora se intensificaram no século XVIII. Hisrich, Peters e Shepherd (2009) destacam que neste mesmo período, o termo era utilizado para se referir às ocupações específicas, porém, a continuidade da evolução foi se ampliando e a figura da pessoa empreendedora tornou-se mais relevante que sua ocupação.

Nessa linha histórica, Landström e Benner (2010) descrevem os principais autores que preconizaram as primeiras concepções sobre empreendedorismo. Uma figura importante foi Richard Cantillon (aprox. 1680-1734), pois suas contribuições descrevem que os empreendedores estavam envolvidos em trocas de mercadorias direcionadas ao lucro e decisões empresariais tomadas em face das incertezas. Uma das características de análise para Cantillon foi a ênfase sobre o "risco e as incertezas" (FILION, 1999; HISRICH; PETERS; SHEPHERD, 2009; BRUYAT; JULIEN, 2000). Filion (1999) e Landström e Benner (2010) descrevem também as contribuições dos franceses, na figura de Jean Baptiste Say (1767-1832), que definia o empreendedor no papel de coordenação de produção e distribuição, ou seja, um coordenador que consistia em combinar os fatores (terra, capital e indústria humana) de produção que resultavam em novos empreendimentos.

Nesse contexto, o empreendedorismo foi evoluindo frente às ideias que dominavam a época, o que proporcionou uma conjuntura quanto a sua evolução. Vale destacar que o contexto da evolução do termo empreendedorismo passa por três eras distintas quanto ao Pensamento Empreendedor. Conforme exposto 
sucintamente na figura 1 abaixo, é possível verificar essa evolução cronológica do processo apresentado por Landström e Benner (2010):

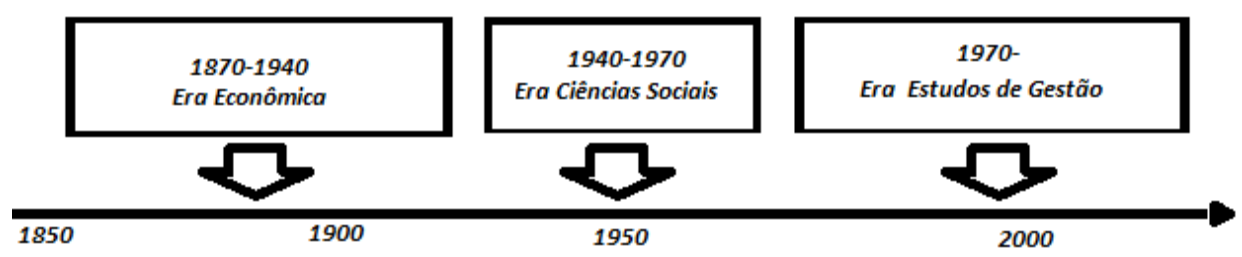

FIGURA 1 - Eras do Pensamento Empreendedor Fonte: Landström e Benner (2010, p. 20).

Na Era Econômica (1870-1940), o interesse pelo empreendedorismo por parte dos economistas vem desde a abordagem de Cantillon e o "risco" (CASSIS, MINOGLOU, 2005; MURPHY; LIAO; WELSCH, 2006), seguida pela tradição Knightian, representada por Frank Knight, com foco nas "incertezas" (CASSIS, MINOGLOU, 2005; DAVIDSSON, 2004; HISRICH, PETERS, SHEPHERD, 2009; JULIEN, 2010). Há, ainda, a Schumpeteriana, provavelmente a mais conhecida na figura de Joseph Schumpeter, que constrói uma nova teoria econômica baseada na "mudança e inovação" (DAVIDSSON, 2004; CASSIS; MINOGLOU, 2005; FILION, 1999; HISRICH; PETERS; SHEPHERD, 2009). Por fim, há a escola Austríaca, destacando que para uma melhor compreensão do empreendedorismo é preciso o esclarecimento da ligação entre o empresário e a empresa (CASSIS; MINOGLOU, 2005).

Por outro lado, a Era das Ciências Sociais (1940-1970) foi um período marcado pela entrada dos estudiosos das áreas de psicologia e ciências sociais, que direcionaram seus interesses no empreendedor como um indivíduo e começaram a investigar suas obras e traços de personalidade. A ênfase do empreendedor no processo de mudança econômica torna-se o objeto de estudo por parte dos sociólogos, figuras como Max Weber são citados por suas contribuições. Já os psicólogos têm o foco nas ciências comportamentais e antropológicas, relacionando o empreendedorismo com um comportamento desviante, ligado à cultura (CASSIS; MINOGLOU, 2005) e também às discussões de pressupostos filosóficos quanto a questões ontológicas, epistemológicas, além do foco sobre a natureza humana e da 
sociedade, que proporcionaram ganhos ao estudo do empreendedorismo (PITTAWAY, 2005).

A Era dos Estudos de Gestão (1970-), por sua vez, foi e está sendo marcada por mudanças políticas, econômicas e tecnológicas. Neste contexto, a dinâmica do empreendedorismo torna-se um tema dominante na sociedade. Para Murphy, Liao, Welsch (2006) ela é reconhecida como a era de base multidisciplinar, pelas pesquisas que envolvem oportunidades, redes de acesso às informações, aos fatores sociológicos, entre outros. Landström e Benner (2010) destacam que muitos estudiosos de diferentes áreas se interessam pelo tema empreendedorismo e que com isso, o campo cresceu consideravelmente. Porém, esse aumento de pesquisa não significa um consenso, apenas reforça a necessidade de pesquisas sistemáticas direcionadas a uma melhor compreensão do fenômeno.

Neste sentido de entendimento, Julien (2010) destaca a importância das raízes do empreendedorismo ligadas a áreas mais antigas e consolidadas, como a economia, ciência do comportamento (psicologia, ciência cognitiva) e sociologia (MURPHY; LIAO; WELSCH, 2006; BARON; SHANE, 2007). A esse respeito, estudiosos do empreendedorismo têm emprestado conceitos e teorias das disciplinas tradicionais, adaptando-os para o estudo do empreendedorismo. Essa importação de outros campos de pesquisa é, muitas vezes, um primeiro passo necessário para criar um campo que posteriormente desenvolve conceitos únicos com teorias próprias (LANDSTRÖM; HARIRCHI; ASTRÖM, 2012).

Quanto a essa discussão, Cassis e Minoglou (2005) relatam que Cantillon, em 1755, já ligava o empreendedorismo às perspectivas das teorias econômicas, sociológicas, psicológicas, antropológicas e ciências políticas. Frente ao contexto apresentado por Julien (2010), destaca-se que para a compreensão do termo, é necessário recorrer a outras disciplinas, não sendo possível restringir-se ao empirismo ingênuo de estudos que se limitam a fazer ligações entre algumas variáveis puramente econômicas.

Nesse sentido, Julien (2010) descreve esse pensamento apoiando-se em quatro abordagens: a antropológica e psicológica, sociológica, geográfica e econômica. É importante citar que estas abordagens não esgotam o assunto, 
apenas delimitam o estudo. O quadro 1 a seguir relata as visões das áreas versus as abordagens, destacando o contexto do empreendedor.

\begin{tabular}{|l|c|c|c|}
\hline ABORDAGEM & $\begin{array}{c}\text { O } \\
\text { ÁREA }\end{array}$ & $\begin{array}{c}\text { A EMPRESA OU } \\
\text { ORGANIZAÇÃO }\end{array}$ & $\begin{array}{c}\text { O AMBIENTE OU } \\
\text { MEIO TERRITORIAL }\end{array}$ \\
\hline $\begin{array}{l}\text { ANTROPOLÓGICA } \\
\text { EUSICOLÓGICA } \\
\text { BEHAVIORISTA }\end{array}$ & $\begin{array}{c}\text { Suas } \\
\text { Características } \\
\text { (origens, cultura, } \\
\text { educação, } \\
\text { formação) }\end{array}$ & $\begin{array}{c}\text { Pessoal e } \\
\text { Centralizada } \\
\text { (dependência do } \\
\text { empreendedor no } \\
\text { inicio) }\end{array}$ & $\begin{array}{c}\text { Pessoal ou não } \\
\text { considerado }\end{array}$ \\
\hline SOCIOLÓGICA & $\begin{array}{c}\text { Um Criador de } \\
\text { Organização }\end{array}$ & $\begin{array}{c}\text { Associada a outras } \\
\text { è sociedade, ela } \\
\text { é mais importante } \\
\text { que o próprio } \\
\text { empreendedor }\end{array}$ & $\begin{array}{c}\text { A organização é parte } \\
\text { do tecido industrial e do } \\
\text { desenvolvimento da } \\
\text { região: gera empregos e } \\
\text { produtos }\end{array}$ \\
\hline $\begin{array}{l}\text { GEOGRÁFICA OU } \\
\text { DE ECONOMIA } \\
\text { REGIONAL }\end{array}$ & $\begin{array}{c}\text { Um dos principais } \\
\text { atores, mas não o } \\
\text { único }\end{array}$ & $\begin{array}{c}\text { Elementos de } \\
\text { diversificação ou } \\
\text { não }\end{array}$ & $\begin{array}{c}\text { Fortes laços com o meio } \\
\text { e vice-versa }\end{array}$ \\
\hline ECONÔMICA & $\begin{array}{c}\text { Simples agente } \\
\text { econômico }\end{array}$ & $\begin{array}{c}\text { Parte da estrutura } \\
\text { setorial e resposta } \\
\text { âs necessidades do } \\
\text { mercado }\end{array}$ & $\begin{array}{c}\text { O dinamismo da } \\
\text { empresa parte da } \\
\text { conjuntura e outros } \\
\text { ciclos econômicos de } \\
\text { médio e longo prazo }\end{array}$ \\
\hline ADMINISTRAÇÃO & $\begin{array}{c}\text { Agente } \\
\text { identificador/criador } \\
\text { de oportunidades } \\
\text { economicamente } \\
\text { viáveis }\end{array}$ & $\begin{array}{c}\text { Combinação de } \\
\text { esforços voltado } \\
\text { para um objetivo }\end{array}$ & $\begin{array}{c}\text { Exerce influencia na } \\
\text { gestão devido a } \\
\text { propensão a atividade } \\
\text { empreendedora }\end{array}$ \\
\hline
\end{tabular}

QUADRO 1 - As diferentes abordagens do empreendedorismo

Fonte: adaptado de Julien (2010, p. 26)

A análise do quadro e as informações descritas possibilitam a conclusão de que o fenômeno do empreendedorismo é complexo demais para ser analisado apenas de um ponto de vista. É preciso destacar a importância dessas abordagens ou até mesmo, se necessário, ir além para melhor compreensão (BARON; SHANE, 2007).

$\mathrm{Na}$ área da Administração, por exemplo, a perspectiva do empreendedor se situa em um contexto de expansão e pesquisas quanto ao papel deste agente como um gestor do seu negócio. Questões quanto ao ato de administrar por parte do empreendedor são necessárias, principalmente devido ao fato de o empreendedor estar no coração da criação e do desenvolvimento de uma empresa (JULIEN, 2010). Com isso, a constituição dessa empresa, em alguns casos, envolvem sonhos, ambições e influências familiares, de modo que a visão da gestão do negócio como 
um todo pode passar despercebida por causa da prioridade na concretização das suas intenções em um negócio rentável.

Diante do contexto apresentado, vale destacar que a descrição das abordagens sobre a evolução do empreendedorismo ligado às distintas eras do pensamento empreendedor torna-se um elemento relevante para o raciocínio do cenário de evolução e discussão do termo. As visões multidisciplinares das raízes epistemológicas da compreensão do fenômeno empreendedorismo possibilita observar a constituição de uma sólida base teórica do assunto. Sendo assim, tornase válido evidenciar que existem outras variáveis ligadas à definição do termo como campo de pesquisa e sua conceituação. Estes elementos são essenciais para a continuidade das discussões sobre o tema.

\section{O CAMPO DE PESQUISA E DEFINIÇÕES DO EMPREENDEDORISMO}

O campo de estudos do empreendedorismo é visto como uma nova ciência e, nesse sentido, Julien (2010) destaca que qualquer pesquisa sobre o tema precisa aplicar o princípio sistêmico da variedade requerida, ou seja, uma abordagem não pode ser menos complexa do que a questão abordada. Quanto à perspectiva de uma nova ciência, Landström, Harirchi e Aström (2012) destacam que o campo de pesquisa sobre empreendedorismo tornou-se alvo de muita atenção ao longo das últimas cinco décadas, o que foi fundamental na construção de sua infraestrutura conceitual. No entanto, é necessária a manutenção dos esforços quanto o que precisamente constitui o empreendedorismo.

Frente a este contexto, é oportuno olhar para trás de forma mais sistemática, analisando o que foi alcançado e tentando identificar as principais contribuições discutidas de forma a se estabelecer uma base para o futuro quanto ao desenvolvimento do empreendedorismo e seu campo. Os autores também destacam a evolução do campo de estudo em três fases distintas, que demonstram a evolução dessa nova ciência.

A primeira, denominada de "Decolagem", diz respeito aos estudos pioneiros sobre o tema, com pesquisas direcionadas para as características do empreendedor e sua personalidade, apoiada em princípios da psicologia, dada à novidade do 
campo. Era fácil para os pesquisadores de diferentes áreas realizarem pesquisas sem experimentar discussões mais analíticas sobre a relevância do estudo. É neste período que se destacam estudos pioneiros de David Birch, como o trabalho The Job Generation Process publicado em 1979, ao relatar que a maioria dos novos empregos na época nos Estados Unidos tinha sido criada por novas e pequenas empresas. Com esses resultados, o impacto no empreendedorismo, na comunidade de pesquisa e nos políticos foi fundamental para a incorporação das pequenas empresas no contexto das políticas do desenvolvimento econômico.

Seguindo, a fase do "Crescimento" esta ligada à construção de uma infraestrutura e à fragmentação da pesquisa, com destaque nos anos de 1990 pelo enorme crescimento das investigações sobre empreendedorismo, o que ocasionou uma disseminação social ampla com o aumento do número de periódicos científicos, conferências, programas educacionais e cursos ligados à área. Os autores relatam que essa década não foi apenas marcada pela migração em larga escala para este campo, os estudos que aconteceram dentro e fora dele, ocasionando consequências no desenvolvimento cognitivo e tornando-se altamente fragmentado, composto essencialmente por trabalho mais empíricos do que teóricos. Neste contexto, Shane e Venkataraman (2000) relatam que o campo de estudo tornou-se um rótulo amplo sob o qual uma mistura de pesquisas foram inseridas. Isto ocasionou, em partes, a perda da legitimidade e algumas dificuldades.

Por fim, há a fase de "Maturidade", após quase 30 anos de intensos estudos sistemáticos. É bem verdade que o campo de estudo sobre empreendedorismo vem se consolidando tanto em um sentido social quanto cognitivo. $\mathrm{Na}$ visão de Landström, Harirchi e Aström (2012), este campo cresceu significativamente e tornou-se um tema popular de interesse entre os estudiosos de muitas disciplinas diferentes. Como consequência, ficou mais heterogêneo, com subgrupos de estudos, movendo-se em direções diferentes, causando certa tensão no interior do campo. Mas como um primeiro passo frente a essas contingências, o artigo seminal de Shane e Venkataraman, The Promise of Entrepreneurship as a Field of Research, publicado em 2000, desencadeou investigações intensas sobre como definir o domínio do campo de pesquisa.

VERGA, E.; SOARES DA SILVA, L. F. Empreendedorismo: evolução histórica, definições e abordagens. Revista de Empreendedorismo e Gestão de Pequenas Empresas, v. 3, n. 3, p. 3-30, 2014. 
Nesse sentido, Bruyat e Julien (2000) reconhecem que o campo de estudos está, em grande medida, formado e com uma comunidade científica ampla. Entretanto, uma questão ainda é relevante: "O campo do empreendedorismo está crescendo ou apenas ficando maior?" (BRUYAT; JULIEN, 2000, p. 166).

Problemas na definição da palavra "empreendedor" e o estabelecimento de limites na área de pesquisa ainda não estão totalmente resolvidos. Muitas pesquisas descreveram o fenômeno de diferentes pontos de vistas, faltando um nível mínimo de consenso na definição do que é o campo e o que não é, além de se criar objetivos claros e temas centrais sobre o assunto.

Para Bruyat e Julien (2000) e Murphy, Liao e Welsch (2006), o objetivo não é propor novas definições, mas integrar as teorias como uma perspectiva de compreensão do fenômeno, limitando o campo em teorias mais estáveis e menos divergentes. Para eles, as definições tornam-se uma ferramenta teórica, uma construção de acordo com os objetivos, levando uma ruptura epistemológica entre o significado geral da palavra e seu significado científico, gerando conhecimentos válidos. Davidsson (2004, p. 1) relata que "um dos fascínios é a riqueza do fenômeno, o que leva a uma das maiores frustrações, por existir a falta de um entendimento comum do que precisamente é o empreendedorismo".

No entanto, apesar do cenário descrito, um passo importante foi dado quanto à definição do termo. Isso porque, a definição de empreendedorismo elaborada por Shane e Venkataraman (2000) se destaca por ter um alto índice de aceitação e ser considerada uma das mais completas e atuais (DAVIDSSON, 2004; CASSIS; MINOGLOU, 2005; BARON; SHANE, 2007; VAGHELY; JULIEN, 2010; HARMELING, 2011; LANDSTRÖM; HARIRCHI; ASTRÖM, 2012; SHANE, 2012).

Para Shane e Venkataraman (2000), o empreendedorismo é definido como o estudo das fontes das oportunidades para criar algo novo (novos produtos ou serviços, novos mercados, novos processos de produção ou matérias-primas, novas formas de organizar as técnicas existentes) e o processo de descoberta, exploração e avaliação, por parte dos indivíduos que as descobrem, avaliando e explorando essas coisas novas, usando diversos meios para se atingir um fim.

Baron e Shane (2007) exaltam a definição de Shane e Venkataraman (2000) como o reconhecimento de uma oportunidade para criar algo novo - e isso não 
precisa ser um novo produto ou serviço, pelo contrário, pode tratar do desenvolvimento de um novo mercado, usando uma nova matéria-prima ou criando um novo meio de produção. Para os autores, o empreendedorismo é visto como uma atividade executada por indivíduos específicos, envolvendo ações chaves (identificação de uma oportunidade - potencialmente valiosa no sentido prático e que possa produzir lucros sustentáveis), e atividades ligadas à exploração e o desenvolvimento real de uma oportunidade.

Neste contexto, Shane e Venkataraman (2000) destacam a importância da compreensão dos dois elementos-chave quanto à definição do termo empreendedorismo: o estudo de fontes das oportunidades - o processo de descoberta, avaliação e exploração (FILION, 1999; DAVIDSSON, 2004; CASSIS; MINOGLOU, 2005; BARON; SHANE, 2007; VAGHELY; JULIEN, 2010), e o conjunto dos indivíduos que as descobrem (FILION, 1999; BARON; SHANE, 2007; HISRICH; PETERS; SHEPHERD, 2009). Uma vez que para os autores, este dois fatores constituem o arcabouço teórico da definição do termo e ao mesmo tempo são elementos fundamentais e presentes nas pesquisas associadas ao empreendedorismo.

Assim, frente ao cenário apresentado, Landström, Harirchi e Aström (2012) destacam que este campo de pesquisa tem crescido, produzindo conhecimento cada vez mais sistematizado, integrado e ancorado em um pequeno conjunto de bases intelectuais. Fato este observado no aceite e disseminação da definição apresentada, o que contribui para o avanço dessa nova ciência, no entanto, ainda há alguns sinais de diferenciação e fragmentação. Nesse sentido, Shane (2012) descreve que este contexto é observado devido ao campo de pesquisa ser complexo, ao passo que não existem fenômenos que o empreendedorismo exclusivamente explica ou prevê.

No entanto, apesar da necessidade da continuidade de pesquisa quanto ao empreendedorismo como campo de pesquisa, um dos principais passos se concretizou a partir da definição para o termo apresentada por Shane e Venkataraman (2000). Isto devido ao amplo aceite por parte de inúmeros pesquisadores como aquela definição mais apropriada para este fenômeno. Vale ressaltar que apesar dessa contribuição fundamental, torna-se evidente a 
necessidade na continuidade das pesquisas, direcionando a temas como a gestão de risco (capital e equipe) e o desenvolvimento econômico proporcionado pelo empreendedorismo (SHANE, 2012).

\section{EVOLUÇÃO DAS PESQUISAS}

Como foi observado, o campo de estudos do empreendedorismo é considerado uma nova ciência. Assim, segundo Julien (2010), pesquisas sobre esse assunto são complexas, mas necessárias para a compreensão do fenômeno. Nesse sentido, a perspectiva do empreendedorismo como um processo e a abordagem effectual são destacadas devido ao fato de evidenciarem proposições que envolvem a criação de novos negócios.

\section{EMPREENDEDORISMO VISTO COMO UMA PERSPECTIVA PROCESSUAL}

Segundo Lichtenstein, Dooley e Lumpkin (2006), o estudo da dinâmica de criação de novas empresas tem sido extensivamente estudado ao nível de mercado, mas moderadamente ao âmbito do empreendedorismo, evidenciando, assim, a amplitude da necessidade de pesquisa nesta área, uma vez que, os projetos existentes podem se estender por décadas. Os autores destacam que esse tipo de análise se torna a pedra angular para os avanços do empreendedorismo.

Para Hisrich, Peters e Shepherd (2009), a busca de um novo empreendimento está incorporado ao processo de empreender. Segundo os autores, esse processo envolve mais do que a simples solução de problemas de posição administrativa, mas também questões como reconhecer, avaliar e desenvolver uma oportunidade (SHANE; VENKATARAMAN, 2000, SHANE, 2012), superando as forças que resistem à criação de algo novo. Esse processo se desenvolve por meio da introdução de novos produtos em mercados existentes ou a introdução de produtos existentes em novos mercados, ou ainda a criação de uma nova organização (LICHTENSTEIN; DOOLEY; LUMPKIN, 2006).

Baron e Shane (2007) descrevem a importância de três níveis de análise no processo que exercem influência, classificando-os em: micro (indivíduo) e macros 
(grupal e social). A individual está ligada a técnicas, motivações, habilidade, talentos e peculiaridades do empreendedor. Já as grupais envolvem as ideias, informação de outras pessoas, interações com capitalistas de risco, clientes e potenciais funcionários. Por fim, há as de nível social, como as políticas governamentais, condições econômicas, mercadológicas e tecnologia.

Assim, para Baron e Shane (2007), a visão do empreendedorismo como um processo (DAVIDSSON, 2004; COPE, 2005), em vez de um evento isolado (HISRICH; PETERS; SHEPHERD, 2009), é relacionada à criação de novas empresas. Para Baron e Shane (2007), esta proposta de visão processual discutida ao longo do tempo, possivelmente ficou mais evidente após o artigo seminal escrito por Gartner, em 1985, por ser o primeiro a combinar as dimensões do indivíduo, ambiente, organização e processo distintamente, mas multidimensionalmente interligadas (COPE, 2005).

Quanto à perspectiva processual, encontra-se a figura de William B. Gartner, autor do artigo A Conceptual Framework for Describing the Phenomenon of New Venture Creation, em 1985. Neste trabalho, Gartner (1985) destacou que o processo de criação de novos empreendimentos integra quatro grandes perspectivas na criação de novos empreendimentos, sendo estas: as características dos indivíduos (individual(s)), a organização (organization) criada por eles, o ambiente (environment) que está em torno do novo empreendimento e o processo (process) pelo qual o novo empreendimento é iniciado.

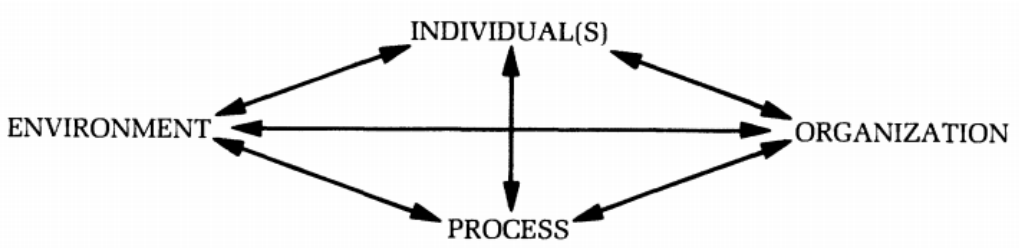

FIGURA 2 - A estrutura para descrever a criação de novos empreendimentos Fonte: Gartner (1985, p. 698)

Sendo assim, Baron e Shane (2007) descrevem que uma das contribuições de Gartner está centrada na combinação das quatro dimensões no processo de criação dos empreendimentos, o que ainda não tinha sido feito. Frente a esse contexto, Bruyat e Julien (2000) evidenciam que a partir dos estudos de Gartner 
(1985) foi possível analisar o processo de uma forma mais densa. Entretanto, para os autores, o empreendedor é o indivíduo responsável pelo processo de criação de novos valores (uma inovação e/ou uma nova organização) e que este novo valor não seria criado sem ele (COPE, 2005; LICHTENSTEIN; DOOLEY; LUMPKIN, 2006). Constitui-se, assim, um sistema dinâmico entre: o indivíduo, o valor criado, um determinado ambiente e o processual, atribuindo a centralidade ao indivíduo e a sua criação.

Dando continuidade, Baron e Shane (2007) descrevem cinco fases distintas para a compreensão deste processo. Os autores alertam que não se trata de um modelo, mas apenas de um conjunto organizado das atividades ligadas ao desenvolvimento de novos empreendimentos.

1. reconhecimento de uma oportunidade: começa quando uma ou mais pessoas a reconhecem (DAVIDSSON, 2004; ECKHARDT; SHANE, 2003; LICHTENSTEIN; DOOLEY; LUMPKIN, 2006; HISRICH; PETERS; SHEPHERD, 2009; SHANE; VENKATARAMAN, 2000; VAGHELY; JULIEN, 2010; SHANE, 2012) e o seu potencial para se criar algo novo (produtos ou serviços, mercados, processos de produção, matérias-primas ou formas de organizar as tecnologias existentes) que surgiu de um padrão complexo de condições em mudanças no conhecimento, tecnologia ou nas condições econômicas, políticas, sociais e demográficas. Baron e Shane (2007) relatam as principais variáveis que podem influenciar o reconhecimento de uma oportunidade: as mudanças sociais e econômicas, desenvolvimento de novos mercados, canais de distribuição e pronta disponibilidade de tecnologia estabelecida e não exclusiva;

Hisrich, Peters e Shepherd (2009) descrevem a importância em se considerar a extensão da janela de oportunidade (período de tempo disponível para criar um novo empreendimento) a partir do reconhecimento e avaliação da oportunidade, enaltecendo que esta análise deve ser centralizada na oportunidade (LICHTENSTEIN; DOOLEY; LUMPKIN, 2006), e não no empreendimento como um todo, fornecendo assim, resultados que contribuam para a decisão de agir ou não antes que essa janela feche.

VERGA, E.; SOARES DA SILVA, L. F. Empreendedorismo: evolução histórica, definições e abordagens. Revista de Empreendedorismo e Gestão de Pequenas Empresas, v. 3, n. 3, p. 3-30, 2014. 
2. A decisão de ir em frente e reunir os recursos iniciais: ter uma ideia e reconhecer uma oportunidade é apenas uma etapa. Visto isso, os futuros empreendedores descobrem que há uma ampla gama de recursos a serem reunidos como, por exemplo, as informações sobre mercados, questões ambientais e jurídicas que, na visão de Vaghely e Julien (2010), contribuem para minimizar as incertezas e riscos. Há também os recursos humanos (sócios e primeiros funcionários) e os recursos financeiros necessários à viabilização do negócio que, segundo Lichtenstein, Dooley e Lumpkin, (2006), são essenciais, principalmente quanto à quantidade e a variedade necessária para o início do empreendimento. É nesse estágio que os empreendedores normalmente preparam um plano de negócio formal com a descrição detalhada de como planejam desenvolver seu empreendimento. Hisrich, Peters e Shepherd (2009) destacam que essa fase possivelmente seja a mais demorada e assim, um bom plano de negócio não é só importante no desenvolvimento da oportunidade, como também essencial na administração bem-sucedida do empreendimento resultante;

3. Lançar um novo empreendimento: assim que os recursos forem reunidos, o empreendimento poderá ser lançado. Mas fazer isso envolve escolher o formato jurídico, desenvolver o novo produto e definir os papéis da equipe. Ocorre que muitos não entendem essa complexidade inicial do novo empreendimento, não dispensando a importância necessária, o que pode sobrecarregá-los com problemas futuros;

4. Construir o sucesso: administrar um novo empreendimento e transformá-lo em uma empresa lucrativa e em crescimento. Nesta fase, apesar de muito empreendedores não admitirem, os recursos humanos são peça fundamental. Atrair e manter funcionários talentosos e motivados é essencial. Manter uma estratégia de negócio é outro aspecto importante, principalmente nos momentos de problemas ou negociações;

5. E colher as recompensas: nesta fase final, os fundadores escolhem uma estratégia de saída que lhes permita colher as recompensas que ganharam pelo tempo, esforço e talento. Existem muitas maneiras de colher esses 
benefícios. Ocorre que os empreendedores precisam escolher cuidadosamente, de forma que maximize os benefícios.

Shane (2012) afirma a importância da perspectiva processual na criação de novos empreendimentos por meio de etapas, esclarecendo que essa atividade não se trata de um modelo racional, planejado ou temporalmente ordenado, mas de um grupo de elementos com subprocessos que nem sempre são executados de forma ordenada. O autor destaca que não existe um padrão lógico e definido para o processo de criação dos novos negócios, como muitos livros didáticos apresentam de forma equivocada essa concepção. Isso porque tanto Gartner (1985) quanto Baron e Shane (2007) relatam que a perspectiva do empreendedorismo visto como um processo não parte de um modelo pré-definido, mas de uma interação entre os elos que constituem a criação de um novo empreendimento. Ou seja, mesmo que o indivíduo seja o elemento principal, na visão de Bruyat e Julien (2000), as demais variáveis são essenciais para a continuidade do processo de criação.

Frente a este contexto, é possível destacar a relação entre as contribuições de Gatner (1985) e Baron e Shane (2007), de modo que se observe uma complementaridade entre ambos os estudos. Gartner (1985) observou que a concepção de um empreendimento se dá por meio de uma inter-relação dos elementos: indivíduo, ambiente, organização e processo. Ou seja, uma visão mais densa a respeito do nível de influência que as variáveis exercem sob o processo de decisão na criação de um empreendimento. Desta forma, os elementos que compõem o ambiente, por exemplo, são agentes influenciadores no processo de criação. Sendo assim, as variáveis apresentadas pelo autor compõe um denso processo de ligação entre ambas destacadas na figura 2. Baron e Shane (2007) destacam uma visão voltada para as fases que envolvem desde a observação da oportunidade à recompensa dos esforços aplicados. Isto significa que essa abordagem está mais próxima da execução das decisões após o processo de interação do indivíduo com os demais elos do processo associados à criação do negócio.

Assim, vistas as ponderações descritas, é possível delinear que as duas perspectivas apresentam características que indicam a complementaridade, uma vez que a inter-relação dos elementos apresentados por Gartner (1985), em um 
nível de análise macro, é relevante para as fases de constituição de empreendimento. Isso porque, na visão de Baron e Shane (2007), a concepção de um negócio, por parte do empreendedor, não advém apenas da identificação de uma oportunidade, mas de um complexo processo interligado que envolve o reconhecimento de uma oportunidade economicamente viável, dadas as variáveis existentes em torno dela. Ou seja, o processo de criar como um todo parte de uma visão ampla quanto à inter-relação dos elementos apresentados por Gatner (1985), passando, após essa identificação, para um nível direcional associado ao indivíduo e ao reconhecimento de uma oportunidade à concretização do processo de criação, descritos por Baron e Shane (2007). Por fim, considerando tais discussões quanto ao processo de criação, vale ressaltar o avanço das pesquisas associadas às abordagens ligadas à gestão.

\section{ABORDAGENS DO EMPREENDEDORISMO: EFFECTUATION versus CAUSAL}

Como observado, o termo empreendedorismo é um fenômeno complexo, mas, por outro lado, essencial no contexto atual. Entender o processo de evolução, as características e visões, torna-se um passo importante para o início de sua compreensão. Assim, um assunto que gera muita discussão e tem sido tratado de forma importante para o progresso nas pesquisas sobre empreendedorismo referese à análise de algumas de suas abordagens mais recentes, enfatizando a distinção entre o raciocínio causal comparado ao effectual.

Sarasvathy (2001) aponta que a grande maioria das teorias e pesquisas sobre empreendedorismo discute a existência de artefatos que dependem de um agente racional para a análise de sua causa-efeito e a posterior tomada de decisão. Contudo, essa ideia clássica, com foco principal na causalidade, não consegue apresentar a fundamentação necessária para se entender o fenômeno do empreendedorismo. Busca-se um entendimento a partir de bases teóricas que possam operacionalizar uma análise comparativa entre as divergências conceituais e as características do raciocínio causal e o effectual (SARASVATHY 2001).

Para Sarasvathy (2008), uma visão mais clara do empreendedorismo é possível quando analisado o enfoque "effectual", e não simplesmente a sua formal 
causal de acontecimento. A autora propõe que para sua abordagem ser eficaz, a preocupação incipiente se deve à análise do mercado, principalmente ao fato de que: "Os empreendedores e gestores devam lidar com os problemas da criação de novos mercados. Além disso, eles frequentemente têm que lidar concomitantemente com a criação dos novos mercados e sobreviver nos mercados já existentes". (SARASVATHY, 2008, p. 97).

Neste sentido, a exploração deste mercado, segundo a autora, deve ser embasada na concepção de Nelson Goodman, que enfatiza um mercado instável e sem a possibilidade de prever o futuro com base no que aconteceu no passado, devido, principalmente, às pessoas apresentarem mudanças que possivelmente modificarão o cenário.

Esta ideologia é ainda ratificada com a determinação de que novos mercados é resultado de um processo isotrópico e que a ação humana transforma a realidade corrente em novas possibilidades (SARASVATHY, 2008). Estas premissas constituem a abordagem Effectuation proposta por Saravasthy e são uma inversão de princípios importantes em teorias causais de empreendedorismo e gestão estratégica. Entende-se, no entanto, que abordagem effectual está mais focada no processo de construção e não no alinhamento de objetivos pré-determinados, como coloca o raciocínio causal.

A lógica effectual prescreve seu raciocínio mediante a utilização e conhecimento dos meios disponíveis para geração de fins ainda não certos (DEW, READ, SARASVATHY, WILTBANK, 2009). O processo effectuation depende da ação humana sobre os meio dados, com vistas a fins não definidos, ou seja, objetivos que podem ser imaginários, mas não predeterminados. Para Sarasvathy (2008), esta abordagem implica na compreensão inicial de que o empreendedorismo não pode ser visto como um fenômeno que dependa de objetivos específicos e determinados, mas deve ser encarado como um conjunto de meios associados a parceiros diversos (stakeholders) que fará com que surjam objetivos diversos.

De acordo com as análises propostas por Sarasvathy (2009), os meios disponíveis e utilizados pela abordagem effectual estão relacionados a três categorias distintas: "Quem eu sou", "o que eu sei fazer" e "quem eu conheço". As próprias características e o traço de personalidade do indivíduo, atrelado a suas 
habilidades e conhecimentos, bem como sua participação em redes sociais, são os pressupostos necessários e disponíveis para a busca de fins ainda não definidos. Comparado a um raciocínio causal, os objetivos finais já são predeterminados e as questões que deverão ser respondidas pelo indivíduo são: "O que eu devo fazer para alcançar os objetivos já propostos? Qual caminho percorrer?".

Segundo Sarasvathy (2009), o raciocínio causal tende a iniciar a sua lógica mediante um universo de todas as alternativas possíveis, procurando restringir o conjunto de escolhas para o melhor, o mais rápido, o mais econômico e os processos mais eficientes. No raciocínio effectual, procura-se expandir a escolha definida a partir de possibilidades localizadas em oportunidades cada vez mais complexas e duradouras, fabricadas em uma forma contingente ao longo do tempo (SARASVATHY, 2009).

Ainda de acordo com Sarasvathy (2009), são destacados quatro princípios básicos da relação effectual, sendo eles:

A. Perdas toleráveis: os empreendedores devem focar suas atenções não nos retornos desejados com o novo negócio, mas o quanto estão dispostos a perder;

B. Alianças estratégicas: no processo de novos negócios, há necessidade da construção de parcerias estratégicas e potências com todos os stakeholders;

C. Exploração de contingências: ao invés de evitar as contingências que possam surgir ao longo do tempo, procura-se explorar, transformando-as em oportunidades;

D. Controle do futuro imprevisível: não se busca a previsão de um futuro incerto, mas a análise e o controle dos recursos disponíveis no início do processo.

Diferente desta abordagem proposta, a lógica Causal tem suas próprias atribuições e divergências quanto ao raciocínio Effectual. Como já descrito acima, o raciocínio da causalidade inicia seu processo por meio de um objetivo dado e que buscará por intermédio dos meios disponíveis, alcançar aquilo que foi proposto de uma forma mais lucrativa, evitando assim, contingências que possam surgir.

De acordo com Sarasvathy (2008), é possível observar algumas características fundamentais entre a abordagem effectual e a causal, muito embora 
a própria autora relate que ambas não são excludentes e certamente são utilizadas em distintos momentos do processo empreendedor. Sendo assim, enquanto a abordagem effectual tende a controlar o futuro, a causal está focada em modelá-lo. Em relação ao mercado, para a perspectiva effectual será construído, no modelo raciocínio causal, este mercado precisa ser analisado. Outro ponto a ser observado é que a abordagem effectuation busca firmar novas parcerias entre a empresa e os agentes externos, enquanto que na causal é nítida a separação entre estes atores.

A abordagem effectual consegue se distinguir da causal principalmente no que diz respeito ao processo de inicialização e desenvolvimento de novos empreendimentos. De acordo com Baron (2009), os empresários têm demonstrado uma forte preferência para a lógica effectual em suas decisões e, no entanto, esta situação não substitui, muito menos extingue a lógica causal.

É fato que ambas as abordagens apresentadas são inerentes ao processo empreendedor e contribuem para a expansão de suas pesquisas. Porém, vale ressaltar que a complexidade do campo em estudo e sua evolução não se restringe apenas a estas abordagens. Assim, estudos relacionados à discussão da influência do empreendedorismo no desenvolvimento econômico tornam-se relevantes por conta da dimensão que esse fenômeno tomou no mundo contemporâneo.

\section{O EMPREENDEDORISMO VISTO COMO UM MOTOR DO DESENVOLVIMENTO ECONÔMICO}

Para o contexto dessa discussão, Naudé (2011) descreve como os estudiosos da economia pensam sobre o empreendedor: é aquele que toma decisões de julgamento sobre a coordenação de recursos escassos e que, na maioria das vezes, está relacionado ao comportamento inovador através da criação e crescimento de uma empresa. $O$ autor destaca que existem duas linhas de pensamentos entre a relação do empreendedorismo e o crescimento. A primeira tem uma visão mais reduzida de desenvolvimento ao igualar o empreendedorismo com o crescimento econômico, a produtividade ou o emprego. A outra possui uma visão ligada a atribuições de papéis ou funções, que incluiu a realocação de recursos, o risco, o ambiente para inovação e a concorrência. 
Segundo Naudé (2011), a primeira visão torna-se mais ampla por não equiparar os elementos presentes, o que a desfavorece e, embora eles sejam importantes, não são suficientes para explicar essa relação. A coordenação dos recursos, a criação de novos negócios e a inovação não necessariamente promovem o crescimento, pois, em alguns casos, são os resultados do crescimento. No segundo ponto de vista, a atribuição de papéis e funções para os empreendedores pode ser vista como algo a "encobrir" os atributos do empreendedor. Essas visões são atribuídas por analisarem apenas resultados individuais. Contudo, esse cenário está mudando ao ponto de exigir uma definição mais ampla de empreendedorismo, como ocorre com os economistas.

Mesmo em um contexto de incerteza quanto a definição do papel do empreendedor na dinâmica econômica, Acs, Desai e Hessels (2008), consideram o empreendedorismo um mecanismo importante para o desenvolvimento econômico através do emprego, das inovações e do bem-estar que ele proporciona. Por outro lado, Hisrich, Peters e Shepherd (2009), afirmam que o seu papel no contexto econômico envolve mais do que apenas o aumento de produção e renda per capita, mas o início e a construção de mudanças nas estruturas dos negócios e da sociedade. Ocorre que essas transformações proporcionadas pelo empreendedorismo são acompanhadas pelo crescimento e por mais produção, permitindo que as riquezas obtidas com essas atividades sejam dividas pelos vários participantes, proporcionando, desta forma, resultados mais expansivos.

Fontenele (2010) esclarece ainda que, apesar do empreendedorismo ter estado um tempo esquecido na teoria do crescimento econômico, sua capacidade de ação foi vital para o progresso econômico, principalmente com as contribuições de Schumpeter em 1934 e as de Kirzner em 1973. As contribuições de Schumpeter destacam a figura do empreendedor na economia, apresentando-o como o promotor do desenvolvimento econômico, graças à sua função de inovador e sua capacidade de realizar novas combinações com os recursos produtivos associados à noção da destruição criativa. Ou seja, passa a explorar oportunidades de forma radical, diferentemente dos padrões mais disseminados na gestão dos negócios para a época.

VERGA, E.; SOARES DA SILVA, L. F. Empreendedorismo: evolução histórica, definições e abordagens. Revista de Empreendedorismo e Gestão de Pequenas Empresas, v. 3, n. 3, p. 3-30, 2014. 
No sentido de esclarecimento de como o empreendedorismo vem se manifestando na economia, Wong, Ping Ho e Autio, (2005) descrevem que ele não ocorre apenas pela entrada em novos mercados, mas também por entradas inovadoras e imitativas em mercados estabelecidos. Para os autores, a essência da literatura associada ao desenvolvimento econômico está vinculada à introdução de inovações, mudanças (novas ideias) e concorrência. Wong, Ping Ho e Autio, (2005) também destacam os múltiplos papéis do empreendedor inovador, que incluem não só a novidade, mas as novas empresas. Uma das hipóteses para esse fenômeno se dá por ceteris paribus, ou seja, com o aumento no número de empreendedores, o crescimento da economia aumenta em nível nacional.

Segundo Wennekers e Thurik (1999), pesquisas empíricas sobre o papel do empreendedorismo como uma força motriz do desenvolvimento da economia não está bem definida, o que demanda mais estudo. No entanto, por outro lado, a proposta de um modelo favorece a compreensão da relação entre o termo e o crescimento econômico, sendo que o quadro conceitual liga as condições existentes (personalidades, culturas, instituições) ao empreendedorismo (multidimensões e diferentes tipos de análises) e este às ligações internas (inovação e competitividade), resultando no crescimento econômico.

Os mesmos autores seguem esse pensamento afirmando que 0 empreendedorismo para o crescimento econômico é associado a dois pontos de vista. No primeiro, o empreendedor é visto como o fundador de um novo negócio, alguém que cria e depois opera essa empresa, mesmo que não exista nada de inovador nesse ato. No segundo, ele desempenha um papel de inovador mais geral, visto como aquele que transforma as invenções e ideias em produtos economicamente viáveis, criando ou explorando uma nova atividade.

Baron e Shane (2007) também destacam três fatores atribuídos aos empreendedores que contribuem para o desenvolvimento. O primeiro é a divulgação dos casos de sucesso relatados pela mídia, tendo como resultados uma aura bastante positiva e atraente. Os empreendedores, de certa forma, se tornam os novos "heróis e heroínas", não sendo surpreendente o número crescente de pessoas escolhendo essa atividade. O segundo é as alterações que ocorrem nas relações de trabalho, impulsionadas pelos cortes dos postos de trabalho e 
reestruturações das corporações, favorecendo um sentimento relacionado a melhores condições de trabalho. Por último, há a concepção dos valores básicos do indivíduo (independência), em especial os jovens, pois preferem um estilo de vida mais independente e que ofereça a possibilidade de escolha ao invés de certezas ou previsibilidade.

Assim, um dos motivos desta ascensão se reflete no crescimento paralelo do número de pessoas que escolhem se tornarem empreendedoras ou que desejam começar seus próprios negócios. Essa tendência ganha força no mundo, principalmente com 0 apoio dos governantes em reconhecerem a força dos empreendedores (BARON; SHANE, 2007; HISRICH; PETERS; SHEPHERD, 2009). Embora nem todos esses negócios possa atender a definição de empreendedorismo, eles contribuem para o desenvolvimento econômico das regiões onde estão instalados, gerando empregos e receitas (BARON; SHANE, 2007).

Outro ponto de destaque nesta discussão está associado aos instrumentos de mensuração da atividade empreendedora. Nesse sentido, o papel do GEM (Global Entrepreneurship Monitor) se destaca, pois este projeto é um dos únicos que a abordagem é voltada para a atividade empreendedora, utilizando de indicadores que medem as atividades, atitudes, condições e aspirações dos empreendedores, fornecendo informações e as dimensões da influência do empreendedorismo nas nações (ACS; DESAI; HESSELS, 2008). Assim, munidos destes dados, os governantes avaliam os avanços da atividade em determinada região, como o número de participantes, por exemplo. Desse modo, a avaliação e a implementação de políticas de estímulos são passíveis de análise a partir das mudanças mensuradas por estes indicadores.

Por fim, após as discussões apresentadas, observa-se a importância do empreendedorismo como um meio para o desenvolvimento econômico, visto que, a criação de um novo empreendimento se torna mais uma fonte impulsionadora da economia por meio da criação de postos de trabalho, como a geração de impostos, por exemplo. Apesar do contexto apresentado, é preciso enaltecer a complexidade sobre a discussão do empreendedorismo como um motor do desenvolvimento econômico. Portanto, os apontamentos apresentados não esgotam muito menos 
limitam o assunto, mas sim apresentam mais uma das inúmeras linhas de pesquisa do fenômeno do empreendedorismo.

\section{CONSIDERAÇÕES FINAIS}

O termo empreendedorismo, apesar de estar presente e ser reconhecido há mais de dez séculos, somente nos últimos vinte anos emergiu significantemente no campo acadêmico, em especial no Brasil. Contudo, só ganhou maior importância a partir da abertura econômica na década de 1990 (PELOGIO; ROCHA; MACHADO; AÑEZ, 2011).

Nessa linha, o presente trabalho apresentou as discussões acerca do empreendedorismo como um campo de pesquisa fundamentado em evolução epistemológica, que no início foram mais esparsas, mas que nas últimas décadas vem apresentando uma coesão teórica. Com isso, críticas em relação ao vácuo intelectual acerca do empreendedorismo são menos frequentes, dado todo o contexto abordado por esse tema. Fatores como a disseminação da definição para o termo favoreceu essa concretização no meio científico.

Quanto à definição, neste trabalho foi apresentada a proposta de Shane e Venkataraman (2000), que descrevem o empreendedorismo como: o estudo das fontes das oportunidades para criar algo novo (novos produtos ou serviços, novos mercados, novos processos de produção ou matérias-primas, novas formas de organizar as técnicas existentes) e o processo de descoberta, exploração e avaliação, por parte dos indivíduos que as descobrem, avaliando e explorando essas novidades, usando diversos meios para se atingir um fim. Esta definição se sobressai frente aos paradigmas relacionados à falta de uma definição clara e bem aceitável sobre este fenômeno.

Os pontos relevantes neste trabalho estão centrados nas discussões quanto à evolução do campo de estudos, associada à perspectiva processual na criação de novos negócios, que teve o seu marco teórico com as contribuições de Gartner, em 1985, ao propor um pensamento multidimensional para essa criação, seguido do amadurecimento da ideia. As discussões apresentadas estão associadas, ainda, às perspectivas apresentadas por Baron e Shane (2007), ao relatarem que o processo 
de criação de um empreendimento envolve desde o reconhecimento de uma oportunidade à concretização do negócio. Ou seja, ambas as visões evidenciam o empreendedorismo como um processo associado a elementos como o indivíduo, ambiente, ambiente e processo. Há de se destacar de forma complementar as contribuições de Bruyat e Julien (2000), pois incluíram a figura do indivíduo como elemento central do processo.

Outro elemento de destaque está associado à evolução do pensamento dos empreendedores com a proposta de Sarasvathy, dirigida ao papel das incertezas na gestão dos empreendimentos. Isto é, uma proposta diferente do modelo causal. Dado que a forma effectual é uma ferramenta associada à gestão a partir das capacidades do empreendedor ligada a questões orientadoras como: quem eu sou, o que sei fazer e quem eu conheço. Estes elementos favorecem uma gestão mais dinâmica a ponto do aceite de perdas toleráveis, no caminho dos objetivos esperados, evidenciando uma forma diferente de ação na atividade.

Por fim, discute-se a abordagem que liga o empreendedorismo ao desenvolvimento econômico, o que evidência a relação entre atividade e empreendedorismo e a evolução econômica. Esta relação é estudada pelo Global Entrepreneurship Monitor, projeto associado à mensuração da atividade empreendedora. Observa-se também algumas limitações neste estudo, o que favorece novas fontes para pesquisas, como: um estudo mais ampliado sobre as eras da evolução, a visão processual e effectual, uma vez que, foram discutidas de forma introdutória no trabalho. Quanto à relação do empreendedorismo e o desenvolvimento, faz-se necessários estudos mais densos, principalmente para compreender a influência desse fenômeno na geração de riquezas na nação, no aumento de novos negócios, na definição de políticas públicas e leis

\section{Referências}

ACS, Z. J.; DESAI, S.; HESSELS, J. Entrepreneurship, economic development and institutions. Small Business Economics, v. 31, n. 3, p. 219-234, set. 2008.

ALDRICH, H. E. The emergence of entrepreneurship as an academic field: A personal essay on institutional entrepreneurship. Research Policy, v. 41, n. 7, p. 1240-1248, set. 2012. 
BARON, R. Effectual versus predictive logics in entrepreneurial decision marking: Differences between expert and novices Does experience in starting new ventures change the way entrepreneurs think? Perhaps, but for now, "Caution" is essential. Journal of Business Venturing, v. 24, n. 4, p. 310-315, jul. 2009.

BARON, R.; SHANE, S. A. Empreendedorismo: uma visão do processo. São Paulo: Thompson, 2007.

BRUYAT, C.; JULIEN, P. A. Defining the field of research in entrepreneurship. Journal of Business Venturing, v. 16, n. 2, p. 165-180, mar. 2001.

CASSIS, Y.; MINOGLOU, I. P. Entrepreneurship in theory and history. New York: Palgrave Macmillan, 2005.

COPE, J. Toward a Dynamic Learning Perspective of Entrepreneurship. Entrepreneurship Theory and Practice, v. 29, n.4, p. 373-397, jun. 2005.

DAVIDSSON, P. Researching entrepreneurship. New York: Springer, 2004.

DEW, N.; READ, S.; SARASVATHY, S. D.; WILTBANK, R. Effectual versus predictive logics in entrepreneurial decision-making: Differences between experts and novices. Journal of Business Venturing, v. 24, n. 4, p. 287-309, jul. 2009.

ECKHARDT, J. T.; SHANE, S. A. Opportunities and Entrepreneurship. Journal of Management, v. 29, n. 3, p. 333 - 349, jun. 2003.

FILLION, L. J. Empreendedorismo: empreendedorismo e proprietários-gerentes de pequenos negócios. Revista de Administração. São Paulo, v. 34, n. 2, p. 05-28, abr./jun. 1999.

FONTENELE, R. E. S. Empreendedorismo, Competitividade e Crescimento Econômico: Evidências Empíricas. Revista de Administração Contemporânea, Curitiba, v.14, n. 6, p. 1094-1112, nov./dez. 2010.

GARTNER, W. B. A Conceptual Framework for Describing the Phenomenon of New Venture Creation. Academy of Management Review, v. 10, n. 4, p. 696-706, 1985.

HARMELING, S. Contingency as an entrepreneurial resource: How private obsession fulfills public need. Journal of Business Venturing, v. 26, n. 3, p. 293305, maio 2011.

HISRICH, R. D.; PETERS, M. P.; SHEPHERD, D. A. Empreendedorismo. Tradução de Teresa Cristina Felix de Souza. 7. ed. Porto alegre: Bookman, 2009.

JULIEN, P. A. Empreendedorismo regional e a economia do conhecimento. Tradução de Maria Freire Ferreira Salvador. São Paulo: Saraiva, 2010.

VERGA, E.; SOARES DA SILVA, L. F. Empreendedorismo: evolução histórica, definições e abordagens. Revista de Empreendedorismo e Gestão de Pequenas Empresas, v. 3, n. 3, p. 3-30, 2014. 
LANDSTROM, H.; BENNER, M. Entrepreneurship research: a history of scholarly migration. In: LANDSTROM, H.; LOHRKE, F. (org). Historical foundations of entrepreneurship research. Great Britain: Edward Elgar Publishing. p. 15-45, 2010.

LANDSTRÖM, H.; HARIRCHI, G.; ASTRÖM, F. Entrepreneurship: Exploring the Knowledge base. Research Policy, v. 41, n. 7. p. 1154-1181, set. 2012.

LANDSTROM, H.; LOHRKE, F. Historical foundations of entrepreneurship research. Great Britain: Edward Elgar Publishing, 2010.

LICHTENSTEIN, B. B.; DOOLEY, K. J.; LUMPKIN, G. T. Measuring emergence in the dynamics of new venture creation. Journal of Business Venturing, v. 21, n. 2, p. 153-175, mar. 2006.

MURPHY, P.; LIAO, J.; WELSCH, H. P. A conceptual history of entrepreneurial thought. Journal of Management History, v. 12, n. 1, p.12-35, 2006.

NAÚDE, W. Entrepreneurship in Not a Binding Constraint on Growth and Development in the Poorest Countries. World Development, v. 39, n. 1, p. 33-41, jan. 2011.

PELOGIO, E. A.; ROCHA, L. C. S.; MACHADO, H. V.; AÑEZ, M. E. M. Criação de Empresas à Luz do Modelo de Decisão effectuation: Um estudo com mulheres empreendedoras no município de Currais Novos/RN. Rio de Janeiro: XXXV Encontro do ANPAD, 2011.

PITTAWAY, L. Philosophies in entrepreneurship: a focus on economic theories. International Journal of Entrepreneurial Behaviour \& Research, v. 11, n. 3, p. 201-221, 2005.

ROESCH, S. M. A. Projetos de estágio e de pesquisa em administração. 2. ed. São Paulo: Atlas, 1999.

SARASVATHY, S. D. Causation and Effectuation: Towards a theoretical shift from economic inevitability to entrepreneurial contingency. Academy of Management Review, v. 26, n. 2, p. 243-288, abr. 2001 a.

SARASVATHY, S. D. Effectuantion: elements of entrepreneurship expertise. Northampton: Edward Elgar Publishing, 2008.

SARASVATHY, S. D. Entrepreneurship as a science of the artificial. Journal of Economic Psychology, v. 24, n. 2, p. 203-220, abr. 2003.

SHANE, S. A. General theory of entrepreneurship: the individual-opportunity nexus. North Hanpton: Edward Elgar, 2003.

VERGA, E.; SOARES DA SILVA, L. F. Empreendedorismo: evolução histórica, definições e abordagens. Revista de Empreendedorismo e Gestão de Pequenas Empresas, v. 3, n. 3, p. 3-30, 2014. 
SHANE, S. Reflections on the 2010 AMR decade Award: Delivering on the Promise of Entrepreneurship as a Field of Research. Academy of Management Review, $v$. 37. n. 1. p. 10-20, 2012.

SHANE, S.; VENKATARAMAN, S. The promise of entrepreneurship as a field of research. Academy of Management Review, v. 25. n. 1. p. 217-226, jan. 2000.

VAGHELY, I. P.; JULIEN, P. A. Are opportunities recognized or constructed? An information perspective on entrepreneurial opportunity identification. Journal of Business Venturing, v. 25, n. 1, p. 73-86, jan. 2010.

WENNEKERS, S.; THURIK, R. Linking Entrepreneurship and Economic Growth. Small Business Economics, v. 13, p. 27-55, 1999.

WONG, P. K.; PING HO, Y.; AUTIO, E. Entrepreneurship, Innovation and Economic Growth: Evidence from GEM data. Small Business Economics, v. 24, n.3, p. 335350, abr. 2005.

Artigo recebido em: 20/07/2014. Artigo aprovado em:21/07/2014

VERGA, E.; SOARES DA SILVA, L. F. Empreendedorismo: evolução histórica, definições e abordagens. Revista de Empreendedorismo e Gestão de Pequenas Empresas, v. 3, n. 3, p. 3-30, 2014. 